\title{
Robust and fast SSFP for the evaluation of LV function at $3 \mathrm{~T}$
}

\author{
Yin Wu*, Fan Yang, Yiu-Cho Chung \\ From 16th Annual SCMR Scientific Sessions \\ San Francisco, CA, USA. 31 January - 3 February 2013
}

\begin{abstract}
Background
3T MRI is advantageous to CMR as it offers higher SNR and better $\mathrm{T} 1$ contrast. Its slow clinical adoption is partly due to the lack of robustness in SSFP cine imaging [1]. Banding artifact in SSFP caused by main field inhomogeneity is common at 3T. Wideband SSFP [2] or prescans (shimming, frequency scout, etc.) are needed to avoid/ reduce the artifact, increasing patient scan time. We propose here to use shorter TR for SSFP through slightly reduced spatial resolution to improve the sequence's robustness and speed for cine imaging. Its ability for LV function assessment was evaluated against the standard SSFP acquisition protocol.
\end{abstract}

\section{Methods}

Protocol

A $600 \mu$ s (instead of $1000 \mu \mathrm{s}$ ) RF pulse and 192 (instead of 256) readout point in SSFP shortened the TR/TE from $3.4 / 1.5 \mathrm{~ms}$ to $2.7 / 1.2 \mathrm{~ms}$. At $40 \mathrm{~ms}$ temporal resolution and $85 \%$ phase resolution, the segments/heart beat increased from 12 to 15 , reducing patient's breath-hold time.

\section{Imaging}

The IRB approved study scanned 8 healthy volunteers (age 26 \pm 2 ) with a 3 T MR scanner (TIM TRIO, Siemens, Germany). Cines of 10 short-axis slices covering the whole heart were acquired with retrogated breath-held SSFP $\left(8 \mathrm{~mm}\right.$ thick, $2 \mathrm{~mm}$ gap, FOV $=340 \times 287 \mathrm{~mm}^{\wedge} 2$, iPAT $=2$, maximum bandwidth). The short TR sequence was used first. Frequency scout was then performed. After that, cine acquisition for the whole heart was repeated using the standard protocol. LV myocardial mass, end-diastolic volume (EDV), end-systole volume (ESV) and ejection

Paul C. Lauterbur Research Centre for Biomedical Imaging, Shenzhen Key Laboratory for MRI, Shenzhen Institutes of Advanced Technology, Shenzhen, China

\section{Biomed Central}

(c) 2013 Wu et al; licensee BioMed Central Ltd. This is an Open Access article distributed under the terms of the Creative Commons Attribution License (http://creativecommons.org/licenses/by/2.0), which permits unrestricted use, distribution, and reproduction in any medium, provided the original work is properly cited. fraction (EF) were analyzed by an experienced observer using QMass MR (Medis, Netherlands) (papillary muscles included). Correlation analysis was performed between paired measurements. Two-tailed paired t-test was conducted to assess the statistical differences with $\mathrm{p}<0.05$ regarded as significant.

\section{Results}

The scan time for 1 slice of cine was about 6 and 9 heart beats for the protocols with short and standard TR respectively. Banding artifact was common in cine images obtained with the standard TR protocol, while images from the protocol using short TR scan were impervious to the artifact. Analysis results were shown in Table 1. Myocardial mass, EDV and ESV from the 2 protocols were very close. The short TR protocol yielded a $1 \%$ reduction in EF compared to the standard one.

\section{Conclusions}

The short TR SSFP cine is more robust to field inhomogeneity at 3T. It eliminates frequency scout and increases patient throughput. Initial results showed that short TR cines gave comparable myocardial mass, EDV and ESV. The measured EF was $1 \%$ lower than the standard protocol, and may be caused by the reduced image spatial resolution. Our preliminary study suggested that by slightly trading spatial resolution for shorter TR in SSFP,

Table $1 \mathrm{LV}$ function measured from the two SSFP protocols.

\begin{tabular}{ccccc}
\hline & Short TR & Standard TR & p-value & $r$ \\
\hline Myocardial mass $(\mathrm{g})$ & $101.2 \pm 12.2$ & $100.2 \pm 12.4$ & $\mathrm{~ns}$ & 0.99 \\
EDV $(\mathrm{ml})$ & $117.4 \pm 20.4$ & $118.0 \pm 19.9$ & $\mathrm{~ns}$ & 0.99 \\
ESV $(\mathrm{ml})$ & $37.8 \pm 8.1$ & $36.8 \pm 7.9$ & $\mathrm{~ns}$ & 0.99 \\
EF (\%) & $67.9 \pm 3.2$ & $68.9 \pm 3.5$ & $<0.05$ & 0.99 \\
\hline
\end{tabular}

Note: ns - not significant. 

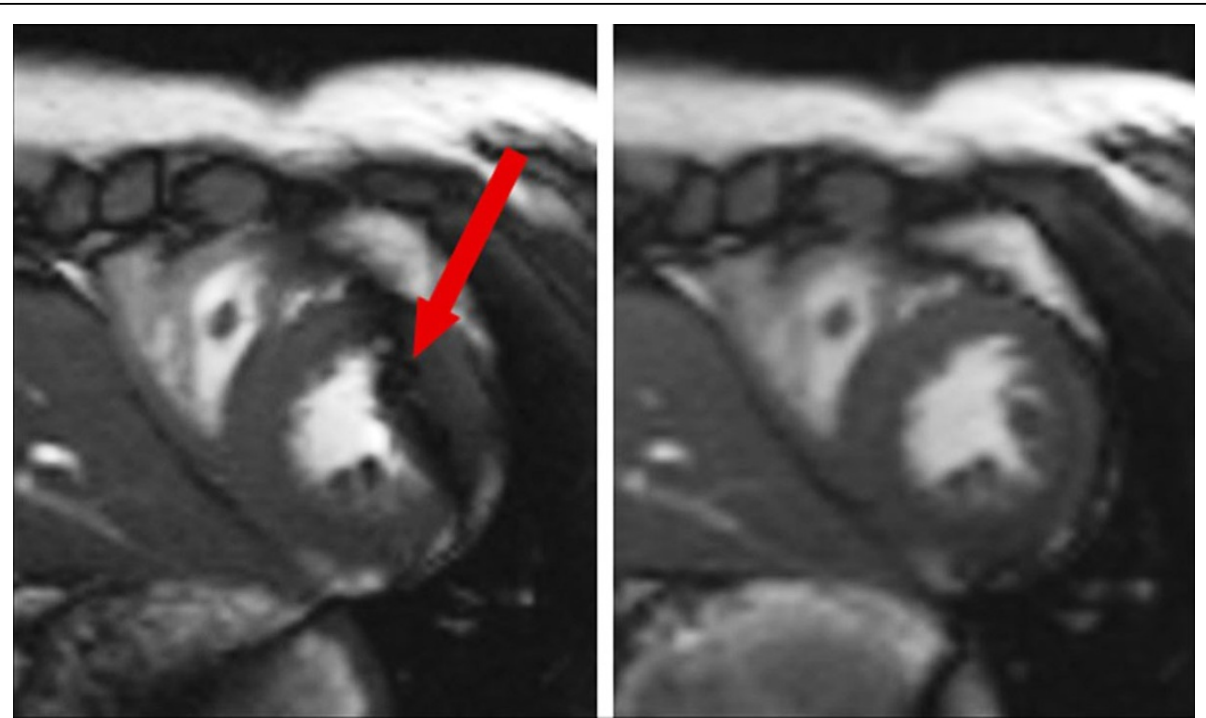

Figure 1 A typical cine image set obtained from SSFP with standard TR (left) and short TR (right). Banding artifact easily appeared in images using the standard TR protocol, while the scan with short TR was impervious to such artifact.

cine imaging at $3 \mathrm{~T}$ can be more robust and efficient. The approach may greatly facilitate patient throughput in $3 \mathrm{~T}$ CMR. Evaluation on more volunteers and patients will be done to fully validate the method.

\section{Funding}

None.

Published: 30 January 2013

\section{References}

1. Oshinski JN, et al: . JCMR 2010, 12:55.

2. Lee $\mathrm{H}$, et al: . MRM 2010, 63(6).

doi:10.1186/1532-429X-15-S1-052

Cite this article as: Wu et al:: Robust and fast SSFP for the evaluation of LV function at 3T. Journal of Cardiovascular Magnetic Resonance 2013

15(Suppl 1):052.

\section{Submit your next manuscript to BioMed Central} and take full advantage of:

- Convenient online submission

- Thorough peer review

- No space constraints or color figure charges

- Immediate publication on acceptance

- Inclusion in PubMed, CAS, Scopus and Google Scholar

- Research which is freely available for redistribution 